ERA DIGTAL

\title{
Co-criadores de marcas
}

1 combinação entre ferramentas de autoria e acesso à internet de alta velocidade tem alterado o monopólio de empresas em relação a suas marcas. Isso quer dizer que a construção da marca, em época de intensa reprodutibilidade digital, não é mais exclusividade de especialistas de marketing: qualquer pessoa, em qualquer parte do mundo, pode co-participar do processo. Analisamos esse fenômeno para as empresas, explorando os paradoxos envolvidos nessa co-criação da marca corporativa.

\section{por Sergio Kul pas Jomalista}

Marshall McLuhan chamou a publicidade de "folclore da sociedade industrial" na década de 1950. Os aforismos de M CLuhan eram sempre crípticos e continham mais do que seu significado aparente. Mas podemos entender 0 termo "folclore" como um conjunto de lendas que todos aprendem desde a infância, recitadas pelos anciãos e pajés da tribo. N aquela época, as ferramentas e meios necessários para difundir imagens e textos sobre produtos comerciais estavam ao alcance apenas das grandes empresas ou das agências de publicidade contratadas pelas empresas.

Essa situação começou a mudar radicalmente com a proliferação dos meios el etrônicos, tornando as ferramentas 
de produção de conteúdo cada vez mais baratas. Some-se a isso a chegada da internet em banda larga, e agora todos os membros da tribo podem fazer folclore.

Multipli cação e visibilidade. Dois amigos, 0 malabarista profissional Fritz Grobe, de 37 anos, eStephen Voltz, um advogado de 48 anos, do vilarejo de Buckfield, no Estado do Maine, EUA, integram um grupo de teatro local, o "O ddfellow Theater". No início deste ano, os amigos criaram um dos mais populares "vídeos virais" nesses tempos de internet em banda larga.

Eles contam que assistiram a um vídeo no qual al guém jogava uma bala dentro de uma garrafa de refrigerante - a reação química faz a garrafa literalmente explodir com a expansão do líquido, criando um jato que pode atingir mais de 10 metros de altura. Eles então decidiram criar uma versão própria da "gag", e assim surgiu o fenômeno "Diet Coke \& Mentos".
Além da reação entre o açúcar da bala e o $\mathrm{CO}_{2}$ do refrigerante, Grobe e Voltz realizaram uma espetacular catálise publicitária: dois cidadãos comuns, não ligados às empresas fabricantes nem a agências conhecidas de publicidade, geraram uma sensação instantânea na web com o vídeo original, que depois se multiplicou em novas versões feitas pelos próprios Grobe e Voltz e em dezenas de cópias e paródias. Assim é o mundo das imagens na era do YouTube.

Para a maioria das pessoas que enviam vídeos para o YouTube, MySpace ou outras comunidades, o sucesso significa que milhares ou até milhões de pessoas vão assistir a sua criação. Por al guns dias ou até semanas, é possível ser famoso nesse universo rápido e volátil. Esse sucesso geralmente não rende dinheiro, mas Grobe e Voltz ganharam mais de US\$28.000 com anúncios no final dos vídeos, de anunciantes como a Microsoft, Warner Home Video e Universal Pictures.

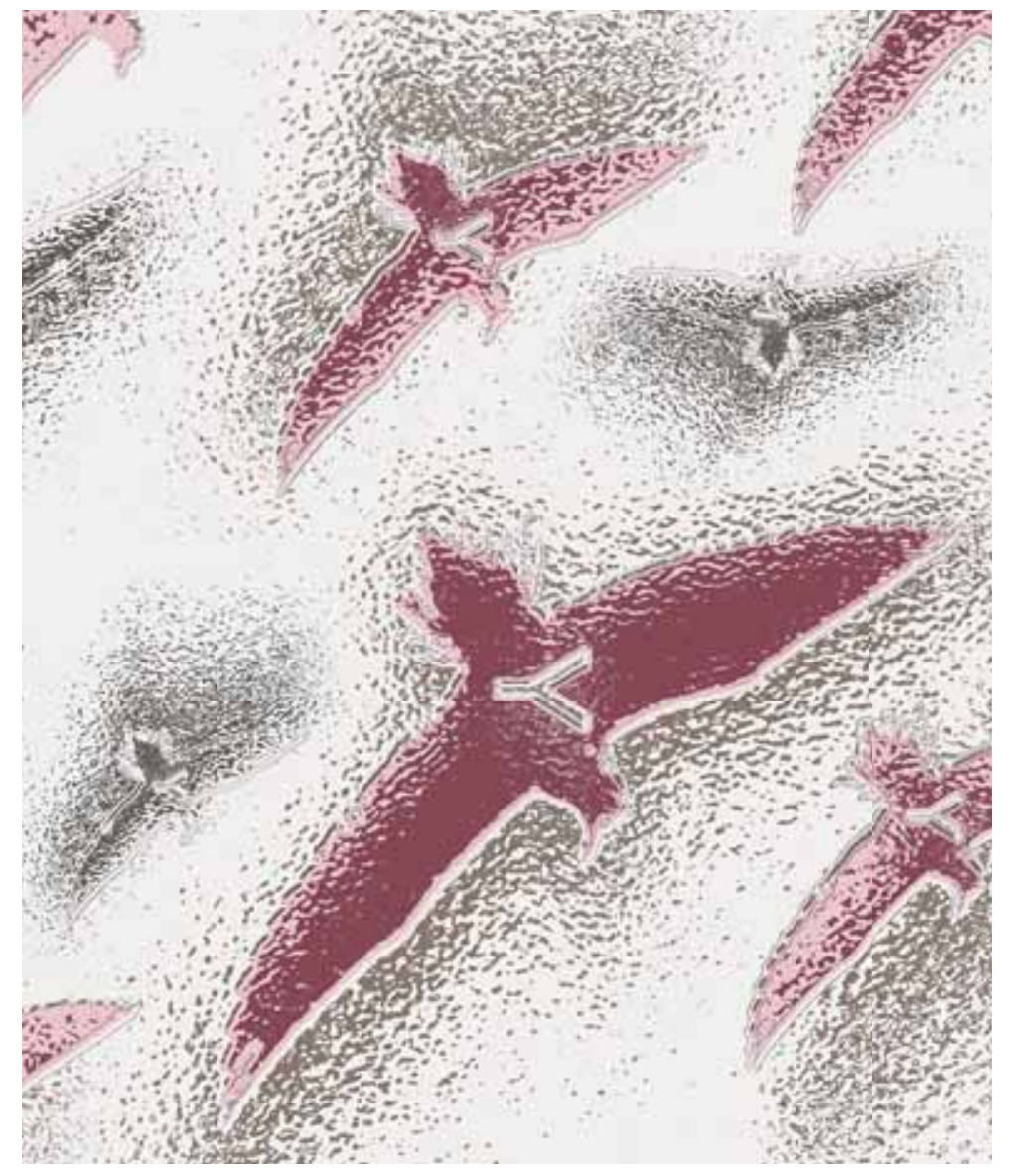

Capitalizando o fenômeno. A empresa que fabrica o Mentos nos EUA, uma unidade daitaliana Perfetti Van M elle, viu no fenômeno uma explosão de popularidade que ela mesma avalia em US\$10 milhões - sendo que a Van Melle gasta menos deUS\$ 20 milhões por ano com publicidadenosEUA. A Van Mellechegou a contar 800 vídeos diferentes no YouTube e similares.

Grobe e Voltz partiram para construções mais elaboradas: na última versão da piada, eles usaram 101 garrafas de 2 litros de Coca diet e 523 drops para criar uma "fonte dançante", imitando a entrada do hotel-cassino Belaggio, de Las Vegas.

A Coca-Cola se mostrou mais blasé a respeito do fenômeno. Uma porta-voz da empresa disse queé "um fenômeno de entretenimento, e preferimos que as pessoas bebam Diet Coke, em vez de fazer experimentos científicos com a bebida". E mais ainda, que "essa loucura com o Mentos não se encaixa na personalidade da marca Diet Coke". Declaração temerária, em uma época em que os consumidores norte- 
americanos estão trocando os refrigerantes diet por água mineral e outras bebidas não carbonatadas.

Apesar da atitude de pretensa indiferença da CocaCola, o fenômeno é indicativo do poder espetacular de multiplicação na era da internet. Dos quase 1.000 vídeos que copiavam o original de Grobe e Voltz, muitos são de locais bem distantes de sua pacata Buckfield, como Israel e China. E observadores da mídia apontaram quea brincadeira de misturar doce com refrigerante com efeito explosivo existe há anos.

U ma das marcas mais características dessa "segunda era" da internet, chamada Web 2.0 por alguns, é que a confluência de ferramentas autorais fáceis de usar e conexões vel ozes permitem um crescimento exponencial de conteúdos amadores, que geram picos enormes de atenção. Milhões de pessoas ao redor do mundo assistiram a um vídeo de fundo de quintal, produzido sem qualquer recurso técnico ou financeiro. Só no site Revver, o vídeo teve cinco milhões de acessos desde maio.

Ao al cance da marca. Atrás da postura aparentemente fria da Coca-Cola, esconde-se um pânico das corporações. As grandes empresas investem muito tempo e milhões de dólares para criar, nutrir e amadurecer uma marca. E a marca é uma entidade "envelopada" em uma enorme estrutura de proteção, sempre atenta a danos e arranhões. As maiores corporações mantêm departamentos inteiros de relações públicas para "apagar incêndios" na imagem de seus produtos. Que o digam a Exxon, a Nike e muitas outras.

Ainda na década de 1990, a Nike criou uma promoção em que os consumidores poderiam personalizar uma frase que seria bordada no par de tênis comprado pela internet. Mas a empresa se viu em uma situação muito intrincada quando os clientes começaram a enviar frases como "Fabricado com mão-de-obra escrava na Ásia" ou "Desrespeitando o meio ambiente", e centenas de outras, com críticas e palavrões.
Em pânico, a Nike começou a recusar as frases, alegando política da empresa, e cancelou a promoção em seguida. Era tarde, o caso chegou à imprensa e causou grande prejuízo. Na época, a Nike se fechou em copas e esperou a tempestade passar. Mas isso foi na primeira era da internet. Hoje, o número de internautas é muito maior, e as empresas temem que os clientes assumam o controle sobre a marca, como um tipo de "aquisição hostil" em termos de mercado. dessa "segunda era" da internet, chamada Web 2.0 por alguns, é que a confluência de ferramentas autorais fáceis de usar e conexões velozes permitem um crescimento exponencial de conteúdos amadores, que geram picos enormes de atenção.

Socializando a marca. 0 navegador Firefox da empresa M ozilla, concorrente do Internet Explorer da Microsoft, éum projeto de "fonte aberta", com pelo menos 1.000 pessoas contribuindo para sua criação e desenvolvimento. A Mozilla Corporation, que distribui o Firefox, resolveu estender o conceito para uma campanha publicitária.

N a campanha "Firefox Flicks", convidou os fãs do navegador a criar comerciais com a duração de 30 segundos e com imagem dequalidade profissional. Esses anúncios seriam avaliados por um painel de profissionais dos setores de TV, cinema e publicidade. A M ozilla recebeu 280 comerciais de todos os cantos do mundo. Além do júri profissional, os comerciais foram votados pelos próprios usuários em uma votação paralela, na qual o comercial favorito teve 29.000 votos. Foi depois visto milhares de vezes no YouTube, ejá inspirou algumas paródias.

Num caso completamente oposto, quando a General Motors pediu que os consumidores criassem um anúncio personalizado para o modelo Chevy Tahoe, 
a fabricante de automóveis se viu na maior saia justa publicitária deste século.

Para resumir a história: a General Motors criou um editando com ferramentas simples imagens do carro Chevy Tahoe, com uma seleção de músicas de fundo. A questão é que 0 site permitia também a adição de legendas sobre as imagens. $\mathrm{E}$ isso desencadeou uma explosão de comerciais que criticavam a marca, o carro, o consumo excessivo de gasolina etc. Os comerciais eram colocados no site da GM, que rapidamente tirou os exemplares mais ofensivos do ar. Mas eles continuaram existindo no YouTube e similares.

0 caso foi amplamente comentado na mídia tradiciocom a iniciativa, a GM experimentou a fina linha entre o fiasco e o sucesso. É um clichê que diz que "não existe os criadores da campanha imaginaram que haveria um número considerável de "antianúncios". A General Motors conseguiu uma grande exposição para o veículo com isso. Mas para tanto teve de abdicar de algo muito importante, que é o controle absoluto sobre a marca. Talvez de modo relutante, a empresa sancionou o uso crítico da marca pelos consumidores. site no qual quem quiser pode criar seu próprio comercial, nal e nos blogs especializados. Muitos observaram que, má publicidade". A empresa não é ingênua. É claro que

os anúncios, mas fazer de conta que não existiam; ou deixar os anúncios e estabelecer um diálogo com esses consumidores. É claro que a primeira opção era a pior, e, a terceira, a melhor. A GM adotou a posição intermediária. Segundo a porta-voz Melisa Tezanos, "a GM antecipou que haveria anúncios criticando o produto. Quando você entrega a marca para o controle público, é de se esperar que venham tanto opiniões boas quanto ruins. Mas isso faz parte de jogar esse jogo". A chave está na afirmação "entregar a marca ao público". E esse jogo será cada vez mais jogado.

Marketing e co-criação. Os profissionais demarketing costumavam ser os sacerd otes que intermediavam a relação entre o consumidor e a Marca Toda-Poderosa, mas agora se fala em "co-criação". Grant McCracken, um escritor e antropólogo, diz que a relação entre os consumidores e as marcas está passando por uma Reforma. McCracken vê essa relação como algo "inteligente e inevitável", mesmo em caso como o do Chevy Tahoe. Segundo ele, acabou a era da marca construída cuidadosamente de modo a não ofender ninguém e agradar a todos.

Os comerciais vencedores da promoção do Firefox, "Daredevil" e "W heee!", foram ambos criados por "quaseprofissionais", estudantes das áreas de cinema e design. Dada a imensa divulgação da campanha, ganhar a promoção vai catapultar as carreiras desses jovens profissionais. "Cocriação" também se confunde com "co-promoção" - são ajudados pela marca que promoveram.

A agência de publicidade ViTrue está lançando, nos EUA,

No blog AdRants, o comentário dizia que sempre haverá opiniões negativas a respeito de qualquer marca ou produto. Entender e aceitar essas visões contrárias pode ser mais benéfico para a marca do que censurar ou ignorar essas opiniões. 0 quea GM pode fazer nesse caso émostrar que é uma empresa "cool", "mesmo que você deteste seus produtos", disse outro blog.

A GM tinha três opções de ação em relação aos antianúncios: del etar os comerciais negativos do site; deixar uma plataforma exclusiva para comerciais criados pelos consumidores. Em vez de criar um software específico, a ViTrue comprou a comunidade de vídeo online Sharkle, um similar do YouTube. E os usuários do Sharkle vão continuar colocando seus vídeos normalmente no site, só que agora podem faturar com isso. A agência quer estimular a criatividade dos internautas, criando concursos de comerciais amadores para al gumas marcas. 
Esti mulando co-produtores. Em uma outra vertente, as marcas estão deixando os consumidores participar não apenas da criação do marketing do produto, mas também do desenvolvimento do próprio produto. Segundo Kirk Olson, consultor de consumo da firma de pesquisas Iconoculture, essa tendência chama-se "fingeprinting" - 0 desejo de participar do produto, acrescentando elementos pessoais em sua produção.

Exemplo disso é a empresa Threadless.com, de Chicago, que fabrica camisetas. A marca promove um concurso de design aberto ao internautas, que enviam seus desenhos para o site. As estampas são depois votadas pelos próprios usuários. Os desenhos mais votados depois de uma semana são impressos em camisetas e vendidos.

A Apple também usa essa tendência em torno de seu produto mais famoso, o iPod. Os usuários podem mandar gravar mensagens no corpo do aparelho, esão estimulados a dar pal pites no design de futuros modelos.

Esse processo é diferente da personalização, ou "customização" de produtos. Segundo a analista Kathy Baylor, na customização um cliente escolhe uma mercadoria já pronta na prateleira e solicita ajustes ou detal hes. Na participação do consumidor, chamada de "customer-made", o cliente participa ativamente do processo de design, até antes de 0 produto chegar ao mercado.

E o fenômeno é mundial. Na Suécia, a famosa marca de móveis Ikea selecionou designs de clientes para uma nova linha de produtos. No Brasil, a Kaiser pediu aos consumidores que enviassem suas preferências de sabor para a cervejaria criar uma nova marca premium. No Tate Britain Museum, de Londres, os visitantes são convidados a escrever legendas para as obras expostas - as frases são selecionadas e colocadas ao lado das obras.

Tendências. A tendência da co-criação de anúncios com os consumidores não está sendo ignorada pelas grandes agências dos Estados Unidos, por mais que ela ameace a posição de "sacerdotes" da comunicação empresarial assumida pelos publicitários. Grandes anunciantes como Chipotle, Converse, Pepsi e MasterCard lançaram campanhas convidando os consumidores a usarem novas tecnologias de vídeo para criar comerciais amadores.

Por exemplo, o salgadinho Doritos (fabricado pela
PepsiCo) motivou uma campanha durante o campeonato de futebol norte-americano que atraiu mais de 1.000 participantes, os quais enviaram seus vídeos. 0 comercial escolhido pelo anunciante apareceu durante os intervalos dos jogos, no horário de maior audiência da TV nos Estados Unidos.

Não apenas os anunciantes estão estimulando os consumidores a criarem comerciais, mas as redes de TV também estão testando a participação do espectador na produção de programas. 0 canal $\mathrm{CW}$, que exibe o seriado adolescente One Tree Hill, fez uma parceria com a Cadbury Schweppes, que produz a linha de refrigerantes Sunkist, para convidar os fãs do seriado a enviar vídeos para o canal. A promoção chama-se "Sunkist Brings 'One Tree Hill' to Your Town Contest" eo prêmio éincomum: uma participação especial em um episódio para o criador do comercial, filmada em locação na cidade natal do vencedor.

Os participantes enviam seus víd eos paraum site criado especialmente para a promoção (cwtv.com/sunkist). Os internautas podem votar nos vídeos, que ficam disponíveis no site. Em menos de duas semanas, foram enviados quase 400 comerciais caseiros. Não é para menos: 0 seriado tem um elenco de jovens excepcionalmente atraentes, que vão contracenar com o vencedor do concurso. Para completar, a audiência de 0 ne Tree Hill é exatamente 0 alvo demográfico dos refrigerantes Sunkist. 0 produtor do seriado chamou esse projeto publicitário de "marketing de 360 graus".

0 ditado do comércio que diz que "o consumidor érei etem sempre razão" não é mais um mero bordão. A questão fundamental ésaber como as empresas vão agir diante deste crescente "empowerment" do consumidor. Podem optar por ignorar essa revolução, perdendo a oportunidade de comunicar intimamente com uma nova geração de consumidores. Pior ainda, podem reagir de forma agressiva, bloqueando qualquer "uso não autorizado da marca", sob pena de processo legal. As empresas e marcas que entenderem que 0 caminho é o diálogo colaborativo com seus clientes terão maior chance de sucesso neste século.

\section{Sergio Kulpas}

Jornalista

E-mail: sergiokulpas@gmail.com 